\title{
Biosensors for Detection of Low-Density Lipoprotein and its Modified Forms
}

\author{
Cesar A.S. Andrade1, Maria D.L. Oliveira2 ${ }^{2}$, Tanize E.S. Faulin³, \\ Vitor R. Hering ${ }^{4}$ and Dulcineia S.P. Abdalla ${ }^{3}$ \\ ${ }^{1}$ Centro Acadêmico de Vitória, Universidade Federal de Pernambuco \\ Vitória de Santo Antão \\ ${ }^{2}$ Departamento de Bioquímica, Universidade Federal de Pernambuco Recife \\ ${ }^{3}$ Departamento de Análises Clínicas e Toxicológicas, Faculdade de Ciências Farmacêuticas, \\ Universidade de São Paulo \\ ${ }^{4}$ Departamento de Bioquímica, Instituto de Química, Universidade de São Paulo \\ Brazil
}

\section{Introduction}

Low-Density Lipoprotein (LDL) is the major carrier of cholesterol in the blood and plays important physiological roles in cellular function and regulation of metabolic pathways. Nevertheless, there are unquestionable evidences that increased plasma levels of LDL, especially their modified particles, are associated with atherosclerosis (Miller et al., 2010; Levitan et al., 2010). Atherosclerosis is a chronic disease that develops progressively through the continuous evolution of arterial wall lesions centered on the accumulation of cholesterolrich lipids, several types of cells and an accompanying immune-inflammatory response (Libby et al., 2009). This disease begins in childhood, progresses relatively silently during adolescence and early adulthood but becomes clinically evident in the middle age or later leading to events such as myocardial infarction and stroke (McGill et al., 2000). The atherosclerotic cardiovascular disease is a major health problem worldwide and the most common cause of death in westernized countries, leading to a substantial economic burden. Whereas the levels of LDL and modified LDL circulating forms in the plasma are important predictive markers to gauge risk of cardiovascular events, there is need to develop reliable rapid assays for quantifying LDL and its modified forms, such as, the biosensors.

In general, biosensor is a measuring system that is composed by two major parts: a recognition part and a transducer part. The recognition part involves biological sensing elements or receptor molecules that lend the sensor specific to a target analyte (Chunta et al., 2009; Cooper \& Cass, 2004; Fowler et al., 2008). A variety of biological substances can be used including antibodies, affinity ligands, isolated receptors, enzymes, organelles, microorganisms, cells, tissues, oligonucleotides, and lipoproteins. When biological substances interact with the target analytes, there is a change in one or more physicochemical parameters such as generation of ions, gases, electrons, second messenger formation, increase or decrease in enzyme activity, heat or mass. The transducer can be used to convert these properties into electrical signal. 
There are three main types of transducers applied to LDL detection: piezoelectric (mass sensitive), optical and electrochemical. Among all types of transducers, the piezoelectric device has been used like LDL sensor. Piezoelectric device, often named quartz crystal microbalance (QCM), shows a very high sensitivity for detecting the target analyte that is placed on the surface of the device and generates the resonant frequency change. A piezoelectric biosensor device has important attractive properties such as small size, rapidity with high throughput, high sensitivity, and specificity. Lipoprotein immunosensors based on piezoelectric technology have been applied to capture and detect ligands on lipoprotein particles (Snellings et al., 2003). At the same time to explore monoclonal LDL antibodies (MAbs) in the interaction with the main protein constituent of human low density lipoprotein (apoB-100) a surface plasmon resonance (SPR)-based biosensor has been employed. Using this technique it is possible to measure the multimolecular complex between MAbs and epitopes of the apoB-100 in real time (Matharu et al., 2009a). The SPR detects and measures changes in refractive index due to the binding and dissociation of interacting molecules at or in proximity to the gold surface. This change of the refractive index is proportional to the concentration of the interacting molecule and causes a shift in the angle of incidence at which the SPR phenomenon occurs.

Electrochemical methods associated with nanomaterials have been employed to develop electrochemical biosensors for the detection of LDL. Cyclic voltammetry (CV) can be used to monitor the biomolecular interaction and explore association between antibody and LDL based on the modification at anodic and cathodic peaks (Stura et al., 2007). CV is an analytical technique to study the electro-activity of compounds, to characterize the redox properties and to provide information about the kinetics of electron transfer reaction of any coupled chemical reaction. Therefore, the advantage of electrochemical impedance spectroscopy (EIS) over other electrochemical techniques is that only small-amplitude perturbations from steady state are needed, and information concerning the interface can be provided (Bockris et al., 2000; Bard \& Faulkner, 2001; Macdonald, 1987). In general, this system has been utilized to fabricate label-free high-sensitivity immunosensors with highly sensitive response to LDL (Yan et al., 2008). Hence, further studies based on LDL biosensors have been directed to diminish the detection time and develop new ways of detecting LDL and modified LDL.

\section{LDL and its modified forms}

The major lipids present in the blood plasma are cholesterol, fatty acids, triglycerides and phospholipids. Cholesterol is present in dietary fat, and can be synthesized in the liver by a mechanism that is under close metabolic regulation. Cholesterol, like all lipids, is not water soluble and thus, it is transported in the plasma in association with proteins (apolipoproteins), forming complexes known as lipoproteins. Lipoproteins are classified on the basis of their densities, which increases from chylomicrons through lipoproteins of very low density (VLDL), intermediate density (IDL) and low density (LDL) to high density lipoproteins (HDL) (Marshall \& Bangert, 2008). The physiological function of LDL particles is to provide cells with the cholesterol they need mainly for steroid hormone synthesis and membrane formation. LDL particles assume a globular shape with an average diameter of about $22 \mathrm{~nm}$ and they are organized into two major compartments. An apolar core comprised primarily of cholesteryl esters, minor amounts of triglycerides and some free unesterified cholesterol surrounded by an amphipathic shell. This outer shell is composed of 
a phospholipid monolayer containing most of the free unesterified cholesterol and one single molecule of apolipoprotein B-100 (apoB-100) (Prassl \& Laggner, 2009). However, LDL particles can undergo in vivo modification by oxidation, glycation, nitration and carbamylation, among other reactions. The extent of LDL modification can range from minimal modification, resulting minimally modified particles, such as the electronegative LDL subfraction (Damasceno et al., 2006), to extensive oxidation. Oxidized LDL is a generic term that describes a variety of modifications of both the lipid and protein components of LDL. Transition metal ions, lipoxygenases, myeloperoxidase, peroxynitrite and other reactive nitrogen and oxygen species derived from this enzyme, among others, have been suggested to be responsible for in vivo oxidative modification of LDL in humans (Stocker \& Keaney, 2004; Malle, et al., 2006). Reactive oxygen species induce fragmentation of apoB-100. The polyunsaturated fatty acids in cholesteryl esters, phospholipids and triglycerides are also subjected to free radical-initiated oxidation to yield a broad array of smaller fragments (Matsuura et al., 2008). This results in a variety of reactive aldehyde products, including (E)4-hydroxynon-2-enal (HNE) and malondialdehyde (MDA), which form covalent adducts with amino acid residues of LDL, generating HNE-LDL and MDA-LDL, respectively (Annangudi et al., 2008; Viigimaa et al., 2010). Glycated LDL is formed by the nonenzymatic covalent binding of reactive aldehydes (from glucose or related species) to a reactive amine (e.g., lysine and arginine side chains) on apoB-100 (Brown et al., 2007). The initial Schiff base undergoes subsequent rearrangement into Amadori products. The Amadori sugar-amino acid adducts can undergo progressive nonenzymatic reactions, leading to the formation of advanced glycation end (AGE) products, resulting in AGE-LDL (Basta et al., 2004; Hodgkinson et al., 2008). LDL can even be modified by urea-derived cyanate. Patients with kidney disease have elevated plasmatic levels of urea. Urea undergoes a spontaneous nonenzymatic transformation to cyanate in aqueous solutions and cyanate can react irreversibly with N-terminal groups of amino acids from LDL by a process known as carbamylation, forming carbamylated LDL (Asci et al., 2008).

The modified LDL forms, independent of the type of modification, triggers various biological responses, including pro-inflammatory reactions potentially involved in atherogenesis, promoting endothelial cell injury, expression of adhesion molecules on endothelium and vascular smooth muscle cell proliferation. Moreover, the modified LDL is uptaken by macrophages via scavenger receptors resulting in the accumulation of cholesterol within the macrophages and the formation of foam cells in the arterial intima. This continuous process lead to advanced lesions in arteries with a core of lipids and necrotic tissue covered by a fibrous cap. Disruption of the cap can lead to thrombosis and many of the adverse clinical outcomes associated with atherosclerosis (Hansson \& Libby, 2006). As the LDL modified forms are proinflammatory and proatherogenic, studies have been done to develop a method to quantify the modified LDL subfraction as a blood biomarker to diagnose cardiovascular diseases and perhaps predict clinical outcomes. Plasma biomarkers have the advantage of being non-invasive and, if abnormal, allow opportunities of early stage intervention.

\section{Methods for measurement of LDL and modified LDL}

A classic method for measurement of LDL is the beta-quantification, which involves ultracentrifugation and a chemical precipitation step (Bachorik, 1997). Because betaquantification is cumbersome and requires sophisticated equipment, in most clinical 
laboratories LDL is usually estimated by Friedewald equation (Friedewald et al., 1972), an indirect method, which estimates the LDL from measurements of total cholesterol (TC), triglycerides (TG), and HDL (Eq. 1).

$$
L D L(m g / d L)=T C-H D L-T G / 5
$$

Despite the simplicity and lack of cost, the error of determining LDL through that estimation comprises the addition of the analytical errors of the three parameters used in the calculus. In addition, the use of that formula has severe limitations and cannot be applied to samples containing TG levels $>400 \mathrm{mg} / \mathrm{dL}$ or in samples with chylomicrons, as occurs in non-fasting samples. Because of the limitations of the Friedewald calculation, some clinical laboratories use enzymatic colorimetric methods for quantification of LDL, which are direct, relatively simple, can be used in automated systems (Cordova et al., 2004; Esteban-Salan et al., 2008) and LDL values are not affected by the presence of increased levels of triglycerides (Rifai et al., 1998). The aforementioned methods quantify the total LDL (modified and unmodified fractions). In the last two decades, aiming to determine the modified LDL subfraction in the blood circulation, ELISAs (Enzyme-Linked Immunosorbent Assay) using monoclonal antibodies were developed. There are ELISAs used in research to measure oxidized LDL (Itabe \& Ueda, 2007) and electronegative LDL (Faulin et al., 2008). ELISA is a method that has high sensitivity and specificity, low cost, technical simplicity, versatility and ability to adapt to different degrees of automation, however, it is a time-consuming test consisting of several steps.

\section{Biosensors}

A biosensor is a physicochemical analytical device for the detection of an interaction of the analyte that combines with a biological component, which recognizes a chemical or physical change, with a detector component that produces a measurable signal in response to the environmental change (Chunta et al., 2009; Cooper \& Cass, 2004; Fowler et al., 2008). The characteristic trait of a biosensor is the direct spatial contact between the biological recognition element (or bioreceptor) and the transducing element (Thevenot et al., 1999). Therefore, biosensor is a measurement device or system that is composed of two major parts: a recognition part and a transducer part (Fig. 1).

A biosensor is an integrated receptor-transducer device, which is capable of providing selective quantitative or semi-quantitative analytical information (Jambunathan \& Hillier, 2003). The biosensor consists, on the one hand, of a biological recognition element, which acts upon a biochemical mechanism, and of a transducer relying on electrochemical, mass, optical or thermal principles.

Typical bioreceptors in biosensors are enzymes, antibodies, lectins, microorganisms and nucleic acids. In addition, the use of biosensors offer several benefits over conventional diagnostic tools as simplicity, specificity, speed, low-cost, portable instrumentation and capability for continuous monitoring in real-time (Freire et al., 2002; Malhotra et al., 2006; Zhao \& Ju, 2006). LDL sensors (lipoprotein sensors) are a new promising group or bioreceptors, because of their outstanding selectivity and stability in responses that provides an evaluation about biomedical diagnosis in plasma LDL levels (Matharu et al., 2009a, $2009 b, 2010)$. New methods for diagnosis of LDL employing biosensors are the current demand to evaluate the risk factors for atherosclerosis. Thus, the basic principles of the 
quartz crystal microbalance (QCM), surface plasmon resonance (SPR), cyclic voltammetry (CV) and electrochemical impedance spectroscopy (EIS) are discussed with the purpose of showing their importance in quantitative or qualitative LDL analysis.

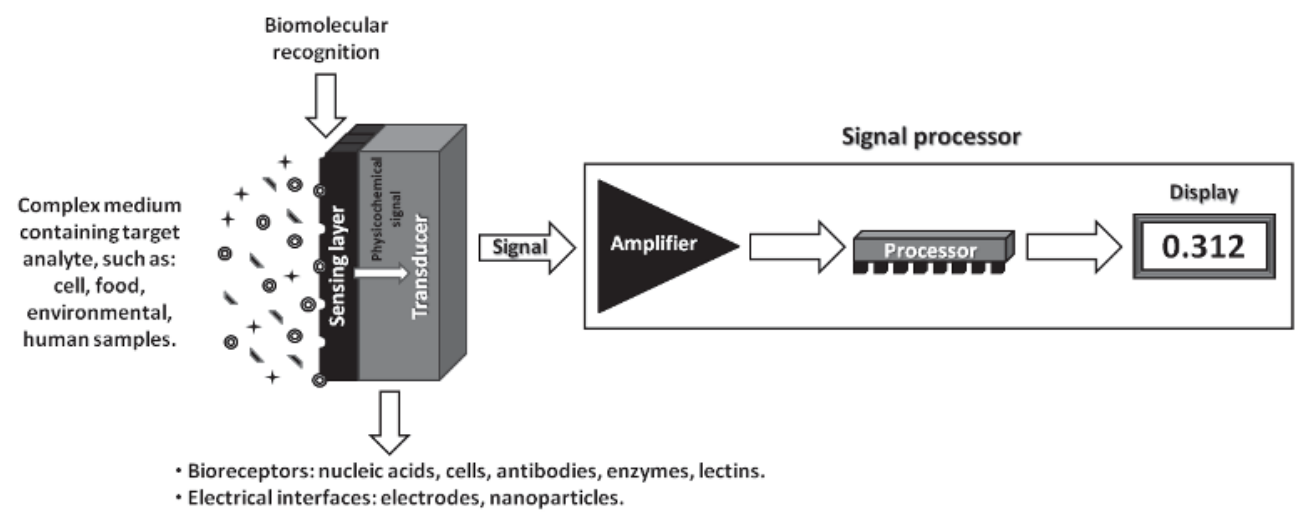

Fig. 1. Schematic diagram of a biosensor. A biosensor consists of a bioreceptor for the specific detection of the respective analyte in spatial contact to a transducer for converting the signal into an electrically manageable format and a signal processing unit.

\section{Quartz crystal microbalance}

Among biosensor devices, piezoelectric has been highly recognized due to their small size, low cost, use of a small volume of sample, high sensitivity, high specificity, rapid response, reproducibility and ease of portable multiple specific sensor array fabrication (Chunta et al., 2009). The QCM is an ultra-sensitive weighing device (to measure or detect a small mass change) that utilizes the mechanical resonance of piezoelectric single-crystalline quartz (Höök \& Rudh, 2005). The piezoelectricity was discovered by Jacques and Pierre Curie in 1880 (Curie J. \& Curie P., 1880a,b) as a potential difference generated across two surfaces of a crystal (including quartz, Rochelle salt and tourmaline) under strain, whose magnitude of electrical potential was proportional to the applied stress (Chunta et al., 2009; Höök \& Rudh, 2005; Smith, 2008). Therefore, piezoelectricity is defined as electric polarization produced by mechanical strain in certain crystals, the polarization being proportional to the strain (Smith, 2008).

Quartz crystals (Fig. 2a) are generally used as weighing devices. Quartz crystal can be cut in different angles which gives different quartz crystal types with specific properties. Typically for piezoelectric analytical work, quartz crystals are cut in the AT form, at a $+35^{\circ} 15^{\prime}$ angle from the Z-axis (Bunde et al., 1998). This geometry has a zero temperature coefficient which provides a stable oscillation with almost no temperature fluctuation in frequency in wide temperature range (Höök \& Rudh, 2005). In addition, quartz is the most commonly crystal used, due to its strong piezoelectric response, abundance, processability, and anisotropy.

QCM is an important technique that has unique advantages for addressing the problems and issues involved in developing these new measurement methodologies (Marx, 2003). The use of the crystal resonator has been extended to numerous applications in different fields like electrochemistry and biology (Arnau, 2008). According to Smith (2008) the resonance 
frequency depends upon the angles with respect to the optical axis at which the wafer was cut from a single crystal and inversely on the crystal thickness.
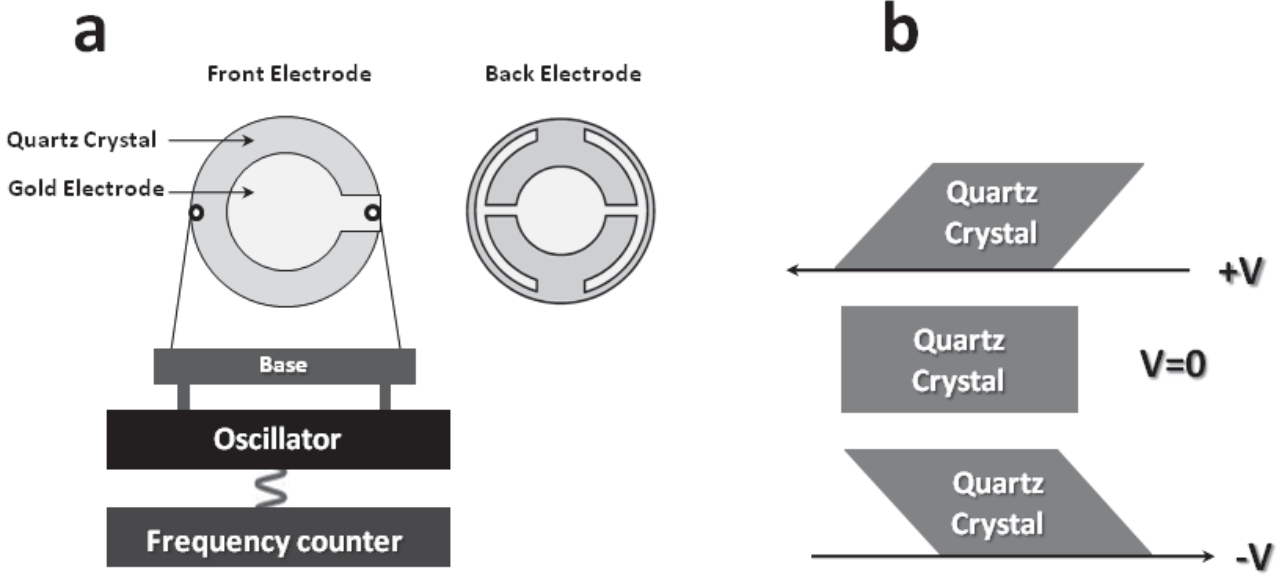

Fig. 2. Experimental apparatus for a piezoelectric system (a) and piezoelectric effect for shear motion (b).

\subsection{Principles of mass measurement}

When an alternating-current (AC) voltage is applied across of AT-cut quartz crystal (Fig. $2 b)$, through opposing electrodes deposited on its surfaces, the resonance is excited if the frequency of the applied voltage corresponds to the resonance frequency $\left(\mathrm{f}_{0}\right)$ of the crystal (Arnau, 2008; Chunta et al., 2009; Höök \& Rudh, 2005; Smith, 2008). It generates a transversal acoustic wave propagating through the quartz to the contacting media and this condition occurs when the thickness of the disc is an odd integer number of halfwavelengths of the standing wave induced between the electrodes, causing the mechanical oscillation to have its anti-nodes at each electrode interface (Höök \& Rudh, 2005). The resonance frequency of the crystal is thus directly proportional to the total mass of the crystal. The frequency range for the fundamental mode of quartz is between 5 and $20 \mathrm{MHz}$ (Marx, 2003). Although, most applications have used QCM devices operating in the 5-10 $\mathrm{MHz}$ range.

A method for correlating changes in the oscillation frequency of a piezoelectric crystal with the mass deposited on it was developed by Günter Sauerbrey (Sauerbrey, 1959). Sauerbrey developed a method for measuring the frequency and its changes by using the crystal as the frequency determining component of an oscillator circuit. The Sauerbrey equation is defined as:

$$
\Delta f=\frac{-2 \Delta m f_{0}^{2}}{A \sqrt{\rho_{q} \mu_{q}}}=-C \Delta m
$$

where $\Delta \mathrm{f}$ is the change in the fundamental frequency $(\mathrm{Hz}), \Delta \mathrm{m}$ is mass change $(\mathrm{g}), \mathrm{f}_{0}$ is the resonant frequency of crystal $(\mathrm{Hz}), \mathrm{A}$ is piezoelectrically active crystal area (area between 
electrodes in $\left.\mathrm{cm}^{2}\right), \rho_{\mathrm{q}}$ is density of quartz crystal $\left(\rho_{\mathrm{q}}=2.648 \mathrm{~g} / \mathrm{cm}^{3}\right), \mu_{\mathrm{q}}$ is shear modulus of quartz for AT-cut crystal $\left(\mu_{\mathrm{q}}=2.947 \times 10^{11} \mathrm{~g} / \mathrm{cm}^{2} \mathrm{~s}^{2}\right)$, and $\mathrm{C}$ is the mass sensitivity constant (based on type of crystal used) (s.g-1).

According to Bunde and collaborators (1998), Sauerbrey's equation is based on the deposition of rigid layers that are infinitesimally thin and, thus, dampen the propagation of the bulk shear wave in a fashion identical to quartz itself. Since the film is treated as an extension of thickness, this approach only applies to systems in which the some conditions are present, as follow: deposited mass must be rigid, uniformly distributed and frequency change $\Delta \mathrm{f} / \mathrm{f}<0.02$ (Srivastava \& Sakthivel, 2001).

This approach was developed for oscillation in air and only applies to rigid masses attached to the crystal. In the beginning of 80 's, scientists have been shown that quartz crystal microbalance measurements can be performed in Newtonian liquid. Kanazawa and collaborators (1985) showed that the change in the resonant frequency of quartz crystal that contacted with the liquid is expressed by:

$$
\Delta f=-f_{0}^{3 / 2}\left(\frac{\rho_{L} \eta_{L}}{\pi \rho_{q} \mu_{q}}\right)^{1 / 2}
$$

where $\rho_{\mathrm{L}}$ is the density of liquid in contact with the crystal and $\eta_{\mathrm{L}}$ is the viscosity of liquid in contact with the crystal (Kanazawa \& Gordon II, 1985).

\subsection{Piezoelectric LDL biosensors}

Lipoprotein biosensors based on piezoelectric technology have been employed to capture and detect ligands on lipoprotein particles. The critical step in LDL detection is the selective separation of LDL from the other lipoprotein fractions (Snellings et al., 2003). A specific ligand for the LDL receptor is apoB-100 (Schumaker et al., 1994), a major apolipoprotein of LDL and a very large glycoprotein consisting of a single polypeptide chain of 4536 amino acid residues with a molar mass of $514 \mathrm{kDa}$ (Yang et al., 1986). The entrapment of LDL in the arterial intima is mainly due to the specific interaction between the lysine-rich sites on apoB100 and the extracellular matrix (ECM) components such as collagen, proteoglycans (PGs), and glycosaminoglycans (GAGs) (D'Ulivo et al., 2010). Valuable techniques already exist for studies on apoB-100 and ECM interactions (D'Ulivo et al., 2009, 2010). In addition, other techniques as affinity chromatography and capillary electrochromatography are available for apoB-ECM interaction studies (D'Ulivo et al., 2009), but new microsystems and miniaturized instrumental tools are desirable to provide complementary information. D'Ulivo and collaborators (2010) explored the applicability of the QCM for interaction studies between apoB-100 peptide fragments and various components of the ECM. They selected three peptide residues from the apoB-100 sequence that are responsible for the binding of LDL with PGs (Skålén et al., 2002). One of these is a water-soluble peptide residue with 19 amino acids, positively charged (net charge of +6 ) that interacts selectively with the LDL receptor (Camejo et al., 1998). The second positive peptide, consisting of 42 amino acids, has a net charge of +3 . This peptide is fairly hydrophobic and soluble only in pure dimethyl sulfoxide and in lipids. Neutral peptide fragment with 11 amino acids was selected as control fragment, since it should not interact with the ECM components (D'Ulivo et al., 2009). Functionalized carboxyl and polystyrene sensor chips were used in this study to 
evaluate the interactions between apoB-100 peptide fragments and components of the ECM. D'Ulivo and collaborators (2010) showed that apoB-100 peptides interact with ECM components via electrostatic interactions, most likely involving their positive residues, lysine and arginine, and that the binding is selective for GAGs.

Others reports describe the use of QCM for on-line monitoring of the adsorption of LDL onto cholesterol-modified dextran (CMD) (Liu et al., 2007). Because LDL particles are the main carries of cholesterol transfer and metabolism, accumulation of LDL is regarded as the first stage of atherosclerotic lesions. These researchers have been engaged in evaluatin the hydrophobic adsorbent, CMD, to investigate the kinetic adsorption curves. Experimental results showed that this system was capable to predict the adsorption capacities and concentrations at ng/ $\mu$ l. Many researchers have been involved in development of different kinds of adsorbents including non-specific, selective adsorbents and immuno-adsorbent according to the molecular structure of LDL (Behm et al., 1989; Bosch et al., 1997).

Piezoelectric technique can be associated to SPR technique to obtain new immunosensor devices. Immunosensors are affinity ligand-based biosensing devices that involve the coupling of immunochemical reactions to appropriate transducers. In recent decades, immunosensors have received rapid development and wide applications with various detection formats (Luppa et al., 2001; Stefan et al., 2000). The general working principle of the immunosensors is based on the fact that the specific immunochemical recognition of antibodies (antigens) immobilized on a transducer to antigens (antibodies) in the sample media can produce analytical signals dynamically varying with the concentrations of analytes of interest. Matharu et al. (2009a) obtained an accurate and specific human plasma LDL immunosensor based on SPR and QCM by immobilizing anti-apolipoprotein B (AapoB) onto self-assembled monolayer of 4-aminothiophenol (AT). The AapoB/AT/Au immunosensor detected LDL up to $0.252 \mu \mathrm{M}(84 \mathrm{mg} / \mathrm{dl})$ and $0.360 \mu \mathrm{M}(120 \mathrm{mg} / \mathrm{dl})$ with sensitivity of $475.39 \mathrm{~Hz} / \mu \mathrm{M}$ and $977.96 \mathrm{~m} / \mu \mathrm{M}$ by QCM and SPR techniques, respectively. The analysis of the values of association constants at different temperatures and the enthalpy of adsorption $\left(\Delta \mathrm{H}_{\mathrm{ads}}\right)$ indicated the AapoB-LDL interaction to be endothermic in nature. The positive value of entropy (T $\left.\Delta \mathrm{S}_{\mathrm{ads}}\right)$ was found to be greater than $\Delta \mathrm{H}_{\mathrm{ads}}$ indicating the adsorption process to be entropy driven. Kinetic, thermodynamic, and sticking probability studies revealed that desorption of water from LDL and AapoB surfaces play the most important role in the binding of LDL to AapoB which enhances with increase in the temperature. In addition, a label-free and reusable AapoB/AT/Au immunosensor was fabricated for estimation of LDL.

\section{Surface plasmon resonance}

Due to the introduction of sensitive bench top instruments and the expansion in the range of strategies for studying biological or biochemical systems (Green et al., 2000; Oliveira et al., 2011) in more recent times, SPR based techniques have found expanded use and recently they have been introduced in clinical studies (Matharu et al., 2009a, 2009b). The competitive advantages of such techniques include the fact that SPR can be applied to a wide range of biomedically relevant interfaces and allows both real-time qualitative and quantitative assessments of the prevailing biomolecular interactions while eliminating the need of labeling reagents and without any complex sample preparation. The use of SPR technique to probe ligand-ligate surface interactions is advantageous, since it is able to rapidly monitor dynamic process, such as adsorption or degradation. SPR provides further information on 
the rate and extent of adsorption, enabling the determination of dielectric properties, association/dissociation kinetics and affinity constants of specific ligand-ligate interactions (Green et al., 2000). In addition, the SPR signal is highly sensitive to even small changes in the refractive index at the interface with a thin noble metal film (Helali et al., 2008). The phenomenon of anomalous diffraction on diffraction gratings due to the excitation of surface plasma waves was first described by Wood (1902). Otto (1968) and Kretschmann \& Raether (1968) demonstrated the method of attenuated total reflection (ATR) for optical excitation of surface plasmons (SP). In the Otto setup, the light is shone on the wall of a prism and totally reflected. In this system a thin metal layer is positioned close enough, that the evanescent waves can interact with the plasma waves on the surface and excite the plasmons. In the case of Kretschmann configuration - widely used within the designs of most SPR instruments - relies on the phenomenon of ATR (Fig. 3). This phenomenon occurs when light travelling through an optically dense medium (e.g. glass) reaches an interface between this medium and a medium of a lower optical density (e.g. air), and is reflected back into the dense medium, and an evanescent wave penetrates through the noble metal layer (Green et al., 2000). The plasmons are excited at the outer side of the film.

\subsection{Theoretical background}

$\mathrm{SPR}$ is a quantum electromagnetic phenomenon arising from the interaction of light with free electrons at metal-dielectric interface, i.e., a charge-density oscillation propagating wave along the interface of two media with dielectric constants of opposite signs (Abdulhalim et al., 2008; Green et al., 2000; Homola et al., 1999; Lundstrom, 1994). A gold film in contact with a water interface is the most common system used in SPR experiments, since gold has a negative dielectric function $(\varepsilon)$ in the infrared and visible regions of the electromagnetic spectrum, whereas water has a positive dielectric function (Johnson \& Christy, 1972). The energy carried by photons of light is transferred to collective excitations of free electrons, called SP, at that interface and this transfer of energy occurs only at a specific resonance wavelength of light when the momentums of the photon and the plasmon are matched (Abdulhalim et al., 2008). This condition is only satisfied at distinct angles of incidence, appearing as a drop in the reflectivity of incident light (Daghestani \& Day, 2010; Novotny \& Hecht, 2006). The field vectors of electromagnetic wave reach a maximum at the interface and decay evanescently with distance normal into a metal (typically gold or silver) and dielectric media. The SP propagates as an electromagnetic surface wave, which is a transverse magnetic-polarized wave (TM-PW). TM-PW can be defined as a magnetic vector perpendicular to the direction of propagation of the ESW and parallel to the plane of interface. Correlating the relationship between the wave vector along the interface and the angular frequency $\omega$, the surface plasmons can have a range of energies that depends on the complex dielectric function of the metal $\left(\varepsilon_{\mathrm{m}}\right)$ and the dielectric function of the adjacent medium $\left(\varepsilon_{\mathrm{d}}\right)$, as shown by the following equation:

$$
k_{s p}=\frac{\omega}{c} \sqrt{\frac{\varepsilon_{m} \varepsilon_{d}}{\varepsilon_{m}+\varepsilon_{d}}}
$$

where $k_{s p}$ is the wave vector of the SP, $\omega$ is the angular frequency, $c$ is the speed of light in a vacuum, and $\varepsilon_{\mathrm{m}}$ and $\varepsilon_{\mathrm{d}}$ are the permittivity of a metal and a dielectric material, respectively (Raether, 1988). In the Eq. 4, the real part determines the SP wavelength and the imaginary 
part determines the propagation length of the SP along the interface, which is responsible for the evanescent field (Daghestani \& Day, 2010).

According to Smith \& Corn (2003) SP can be directly excited by electrons; however, they cannot be excited directly by light because they have a longer wave vector than light waves of the same energy $\left(k_{\text {light }}=\omega / c\right)$. The wave vector of a photon must be increased to convert the photon into SP. A monochromatic p-polarized light source is used in SPR measurements and the interface between the two optically dense media is coated with a thin metal film (Fig. 3). The Eq. 4 under conditions of ATR (Kretschmann configuration) becomes,

$$
k_{\text {ATR }}=\frac{\omega}{c} \sin \theta \sqrt{\varepsilon_{p}}
$$

where $\varepsilon_{\mathrm{p}}$ is the dielectric constant of the prism, and $\theta$ is the angle of incidence of the light on the metal film (Raether, 1988).

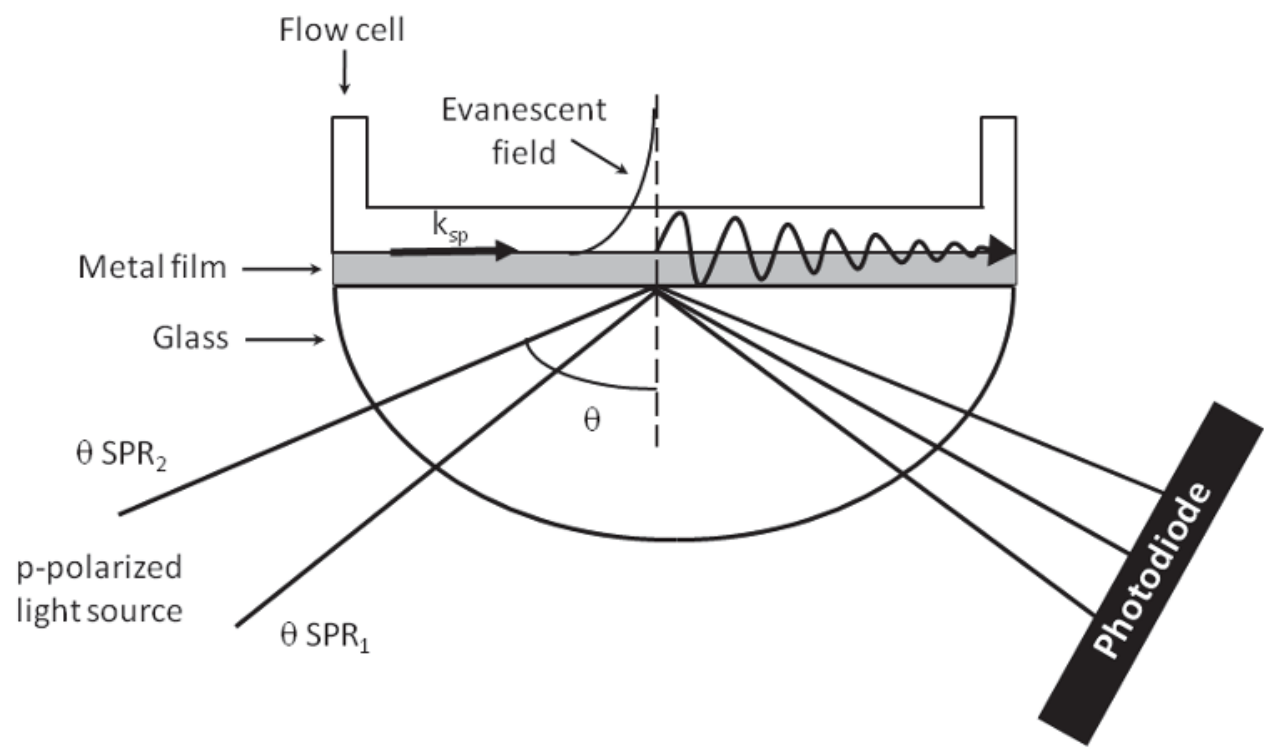

Fig. 3. Schematic diagram of SPR Kretschmann configuration. $\theta S P R_{1}$ and $\theta S P R_{2}$ represents the relation of SPR angle in the absence and presence of species on the metallic surface, respectively.

When the parallel component of the incident light is equivalent to the SP propagation constant, i.e., $\mathrm{k}_{\mathrm{SP}}=\mathrm{k}_{\mathrm{ATR}}$ (Eq. 4 and 5) a drop in reflectance will be found, due to the formation of an evanescent wave, that propagates through the metallic surface and interacts with the external medium (Damos et al., 2004), as follow:

$$
\frac{\omega}{c} \sqrt{\frac{\varepsilon_{m} \varepsilon_{d}}{\varepsilon_{m}+\varepsilon_{d}}}=\frac{\omega}{c} \sin \theta \sqrt{\varepsilon_{p}}
$$

which can be rewritten as 


$$
\left.\theta=\arcsin \left(\sqrt{\left(\frac{\varepsilon_{m} \varepsilon_{d}}{\varepsilon_{m}+\varepsilon_{d}} \times \frac{1}{\varepsilon_{p}}\right.}\right)\right)
$$

In this last expression it can be seen that the system optical properties, like the metal, prism and matrix dielectric constants, induce changes in the resonance angle, making it possible to apply the SPR phenomenon to monitor changes in the sensor surface (Damos et al., 2004). SPR technique relies on the principle that any changes on the dielectric sensing surface will cause a shift in the angle of reflectivity, followed by a detector, in order to satisfy the resonance condition (Daghestani \& Day, 2010).

\subsection{SPR measurement}

In a simple SPR measurement, a target component or analyte is captured by the capturing element or so-called ligand and this ligand is permanently immobilized on the sensor surface previous to the measurement. The direct detection is the event of capturing the analyte by the ligand gives rise to a measurable signal. For each measurement, the surface is primed with a suitable buffer solution to create a baseline on the SPR curve (Green et al., 2000). It is of vital relevance to have a reliable baseline before the capturing event starts (Tudos \& Schasfoort, 2008). Once the biomolecule comes into contact with the surface, rapid adsorption occurs resulting in an increase in the SPR angle and is followed by a plateau in the adsorption profile due to saturation of the surface (Fig. 3a). Finally, the biomolecule solution is replaced with a buffer to remove loosely bound material. The difference between the $\theta S P R_{1}$ to $\theta S P R_{2}$ gives an indication on the extent of adsorption (Fig. $3 b$ ), and the positive gradient of the SPR adsorption curve determines the rate of adsorption (Damos et al., 2004; Green et al., 2000; Tudos \& Schasfoort, 2008).
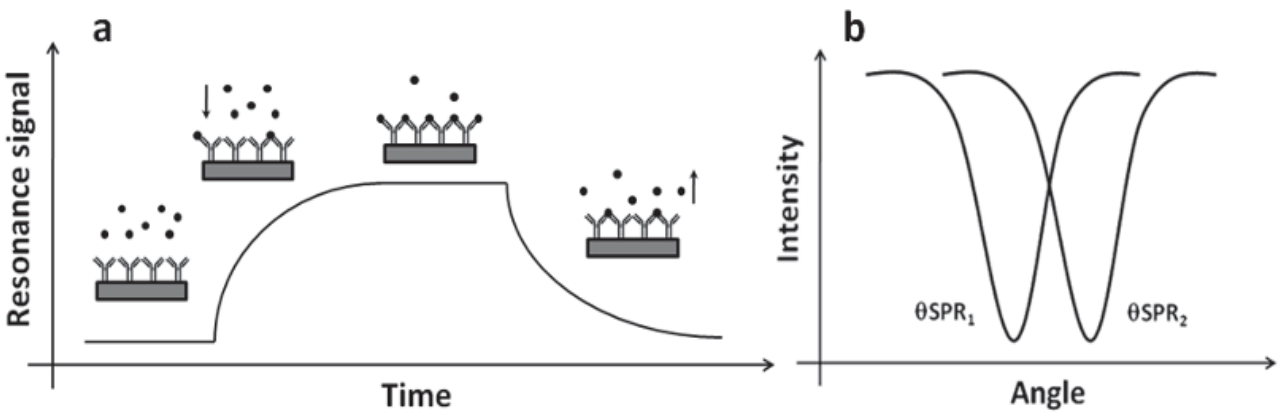

Fig. 3. Sensorgram showing the steps of an analysis cycle of association and dissociation steps (a). A change in refractive index at the surface of the metal film will cause an angle shift from $\theta S P R_{1}$ to $\theta S P R_{2}(b)$.

Often SPR measurements are carried out to determine the kinetics of a binding process. For realistic results it is vital to prevent immobilization from changing the ligand in a way that would influence its strength or affinity towards the target component (Tudos \& Schasfoort, 2008). 


\subsection{Optical LDL biosensor}

The SPR detects and measures changes in refractive index due to the binding and dissociation of interacting molecules at or in proximity to the gold surface. This change of the refractive index is proportional to the concentration of the interacting molecule and causes a shift in the angle of incidence at which the SPR phenomenon occurs. In addition, to explore monoclonal LDL antibodies in the interaction with the main protein constituent of human LDL (apoB-100) is possible to use a SPR-based biosensor to measure the multimolecular complex between MAbs and epitopes of the apoB-100 in real time.

Robbio and collaborators (2001) using a SPR-based biosensor, studied the interaction of ten different murine MAbs (all $\mathrm{IgG}_{1}$ ), raised against apoB-100. These MAbs identify distinct domains on apoB-100, relevant to LDL-receptor interaction: epitopes in the amino-terminal region and in the middle region of native apoB-100. A multisite binding analysis was performed to further characterize the epitopes recognized by all these MAbs. The capacity of each MAb to interact with the entrapped apoB-100 in a multimolecular complex was monitored in real time by SPR. The results achieved were comparable to those obtained by western immunoblotting using the same reagents. However, SPR ensures a more detailed epitope identification, demonstrating that SPR technology can be successfully used for mapping distinct epitopes on apoB-100 protein in solution dispensing with labels and secondary tracers.

In another study, some authors (Gaus \& Hall, 2003) have been investigating the use of peptides for the development of new LDL biosensor. Gaus \& Hall (2003) selected short peptides sequences that showed binding selectivity towards native and oxidized LDL. Peptides were investigated for application in atherosclerosis risk monitoring using SPR technique. The peptides were immobilized on a gold SPR surface and LDL binding detected as a shift in the resonance. $3.7 \times 10^{7}\left( \pm 5.6 \times 10^{6}\right) \mathrm{LDL} / \mathrm{mm}^{2} / \mu \mathrm{g} / \mathrm{ml}$ solution LDL were bound on GlySerAspGlu-OH and $6.8 \times 10^{7}\left( \pm 9.2 \times 10^{6}\right) \mathrm{LDL} / \mathrm{mm}^{2} / \mu \mathrm{g} / \mathrm{ml}$ on GlyCystineSerAspGlu, compared with $\sim 10^{8} \mathrm{LDL} / \mathrm{mm}^{2} / \mu \mathrm{g} / \mathrm{ml}$ on LDL receptor ligand repeat peptide. They found a good correlation between LDL binding on these ligands and residual amino groups on the apoprotein of the LDL, which is an indicator of oxidation level. A very small sample $(20 \mu \mathrm{l})$ could be taken for analysis and diluted 1:20 with physiological buffer prior to assay (giving total volume $0.4 \mathrm{ml}$ ). In addition to the obvious advantage in the required sample size, this has the effect of diluting potential plasma protein interference to levels where they no longer gave a significant background SPR response.

According to Laffont et al. (2002) glycation is responsible for disruption of lipoprotein functions leading to the development of atherosclerosis in diabetes. Glycation is the result of the irreversible attachment of sugar moieties to $\mathrm{NH}_{2}$-protein groups, and is believed to play an important role in cardiovascular disease development among diabetic population through an impairment of lipoprotein functions. Glycation of lipoproteins as VLDL and HDL also affects their functional activities. Glycated VLDL display a higher residence time in plasma, are poorer substrates for lipoprotein lipase than non-glycated VLDL (Mamo et al., 1990), and glycation impairs paraoxonase activity in HDL (Hedrick et al., 2000). Laffont et al. (2002) also studied the effect of the early-glycation of apoE2, apoE3 and apoE4 on their binding to receptors. Glycated apoE binding to heparin and heparan sulfates (HS) was assessed by SPR technology (Laffont et al., 2002). Site-directed mutagenesis was then performed on Lys-75, the major glycation site of the protein. The prepared mutant protein proved to be useful as a tool to study the role of Lys-75 in apoE glycation. The results showed that, although glycation has no effect on apoE binding either to the LDL receptor 
(LDL-R) or to scavenger receptor A (SR-A), it impairs its binding to immobilized heparin and HS. The glycation of Lys-75 was found to proceed rapidly and contributed significantly to total protein glycation. Laffont et al. (2002) showed that the glycation of Lys-75, a major glycation site in apoE, is a rapid process which contributes significantly to total apoE glycation. Although the glycation of apoE has no effect on its binding either to LDL-R or to SR-A, it impairs all three common apoE isoforms that bind to HS.

Some authors (Kudo et al., 2001) have previously shown that Asp-hemolysin binds to oxidized LDL (OxLDL) in a concentration-dependent manner. They investigated the relationship between the oxidation extent of LDL and its binding activity to Asp-hemolysin, to assess the binding specificity of Asp-hemolysin for OxLDL with several scavenger receptor ligands and to attempt the real-time kinetic measurement of the Asp-hemolysinOxLDL interactions and calculations of the kinetic constants from SPR results. They showed that Asp-hemolysin has high affinity binding protein for OxLDL, and its binding specificity is distinct from any receptor for OxLDL. SPR studies revealed that OxLDL binds with high affinity $\left(K_{D}=0.63 \mu \mathrm{g} / \mathrm{ml}\right)$ to Asp-hemolysin. These studies suggest that Asp-hemolysin may bind to OxLDL using a mechanism different from the scavenger receptors.

The self-assembly of molecular building blocks into ordered nanostructures is not only a key to various biological phenomena, but also an attractive route for fabricating novel biosystems. Choi et al. (2004) developed an antibody-based immunoassay system to detect LDL. The self-assembled monolayer of 11-mercaptoundecanoic acid (11-(MUA)) and hexanethiol mixture was fabricated to form the stable protein G layer. 3[(cholamidopropyl)dimethyl-ammonio]-1-propane sulfonate (CHAPS) was used for the regulation of protein $G$ aggregate immobilized on the 11-(MUA) surface. The generic property of CHAPS made it possible to regulate the amount of protein immobilized on the surface. The anti-LDL layer on self-assembled protein G using CHAPS was applied to SPR immunosensor for detection of LDL and its detection limit was $100 \mathrm{pM}$. The relation with the change of SPR minimum angle and surface structure of fabricated layers with respect to the introduction of CHAPS implicate the importance of molecular control for the enhancement of immunosensor performance.

Although, some authors (Snellings et al., 2003) have fabricated an acoustic wave biosensor for detection of lipoprotein fractions using dextran sulfate (DS) modified self-assembled monolayer of 11-mercapto-1-undecanol on gold (Au) surface, it has been found that DS coating is more selective to LDL fraction as compared to other lipoprotein fractions. However, the authors could not achieve reproducibility for coating DS onto a similar surface and the sensor lacked specificity.

Lectin-like OxLDL receptor 1 (LOX-1) is the major OxLDL receptor of vascular endothelial cells and is involved in an early step of atherogenesis (Sawamura et al., 1997). LOX-1 is a membrane protein with a type II orientation consisting of four domains and the extracellular part of LOX-1 comprises an 82-residue stalk region (NECK) and a C-type lectin-like ligandbinding domain (CTLD). The CTLD is connected to the NECK domain that has a coiled-coil sequence, which promotes LOX-1 homodimerization (Ishigaki et al., 2007). Ohki and collaborators (2010) revealed the functional significance of the clustered organization of the ligand-binding domain of LOX-1 with SPR. They have been used biotinylated CTLD immobilized on a streptavidin sensor chip to make CTLD clusters on the surface. Their results showed that a single homodimeric LOX-1 extracellular domain had lower affinity for OxLDL in the supramicromolar range of dissociation constant $\left(\mathrm{K}_{\mathrm{D}}\right)$. Single LOX-1 receptor 
per se does not exert the full binding ability to OxLDL. Monomeric CTLD has shown rather marginal binding to OxLDL. A multivalent interaction between the clustered LOX-1 and OxLDL should be essential to gain biologically significant binding activity. The experiment with the W150A (W150 residue locates at the dimer interface) mutant suggested that each LOX-1 in the cluster must retain the proper CTLD dimer; otherwise, LOX-1 loses the binding activity to OxLDL. Regarding the reduced activity of W150A, Ohki et al. (2010) cannot rule out the possible contribution of the "hydrophobic tunnel" that runs through the dimer interface of the CTLD. This tunnel is proposed to be engaged in OxLDL recognition. Ohki et al. (2010), in combination with the analyses on the loss-of-binding mutant W150A, concluded that the clustered organization of the properly formed homodimeric CTLD is essential for the strong binding of LOX-1 to OxLDL. It was important to evaluate and understand the mode of LOX-1 binding to OxLDL to explain the initial step of atherogenesis.

\section{Electrochemical techniques}

An important point to electrochemical sensor design lies in the molecular understanding of the relationship between surface structure and reactivity. The fabrication of sensor materials with unique response characteristics has created a pressing need to understand their chemical and physical properties. Understanding the fundamental process that govern sensor response in most cases leads to the development of electroanalytical devices with superior selectivity, excellent chemical stability, higher sensitivity, and lower detection limits. In order to meet these needs, it has been necessary to study various electrical processes that occur at the surface of the sensor or inside the sensor matrix itself. Electrochemical biosensors constitute a rapidly growing area of interest to biotechnologists. These devices combine the analytical power of electrochemistry with the specificity of biological molecules for particular substrates.

\subsection{Cyclic voltammetry}

Voltammetry belongs to a category of electro-analytical methods, through the information about an analyte that is obtained by varying a potential and then measuring the resulting current (Brett \& Brett, 1993). It is, therefore, an amperometric technique. Since there are many ways to vary a potential, there are also any forms of voltammetry, such as: polarography, linear sweep, differential staircase, normal pulse, reverse pulse and more (Brett \& Brett, 1993; Bard \& Faulkner, 2001).

Cyclic voltammetry (CV) measurements are the current signals based on the electrochemical species consumed and/or generated during a biological and chemical interaction process of a biologically active substance and substrate (Oliveira et al., 2009; Oliveira et al., 2011). CV is one of the most widely used forms and it is useful to obtain information about the redox potential and electrochemical reaction (e.g. the chemical rate constant) of analyte solutions (Brett \& Brett, 1993). In this case, this voltage is swept between two values at a fixed rate, however, when the voltage reaches $V_{2}$ the scan is reversed and the voltage is swept back to $\mathrm{V}_{1}$, as is illustrated in Fig. 4a. The scan rate, $\left(\mathrm{V}_{2}-\mathrm{V}_{1}\right) /\left(\mathrm{T}_{2}-\mathrm{T}_{1}\right)$, is a critical factor, since the duration of a scan must provide sufficient time to allow for a meaningful chemical reaction to occur. Varying the scan rate, therefore, yields correspondingly varied results (Bard \& Faulkner, 2001). 
a

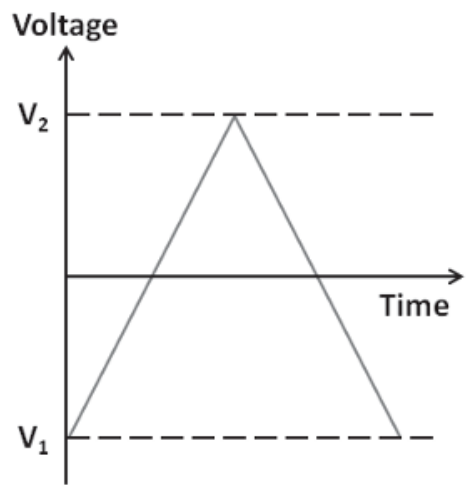

b

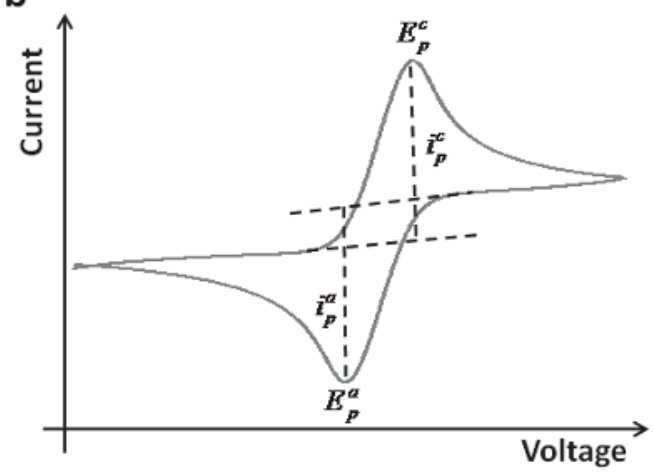

Fig. 4. Cyclic voltammetry waveform (a) and typical cyclic voltammogram (b). $E_{p} c\left(E_{p} a\right)$ and $\mathrm{i}_{\mathrm{p}} \mathrm{c}\left(\mathrm{i}_{\mathrm{p}} \mathrm{a}\right)$ are the potential and current at cathodic (anodic) peak, respectively.

The voltage is measured between the reference electrode and the working electrode, while the current is measured between working electrode and the counter electrode. The obtained measurements are plotted as current vs. voltage, also known as a voltammogram. As the voltage is increased toward the electrochemical reduction potential, the current will also increase. With increasing voltage toward $V_{2}$ past this reduction potential, the current decreases, having formed a peak as the analyte concentration near the electrode surface diminishes, since the oxidation potential have been exceeded (Brett \& Brett, 1993). As the voltage is reversed to complete the scan toward $V_{1}$, the reaction will begin to reoxidize the product from the initial reaction. This produces an increase in current of opposite polarity as compared to forward scan, but again decreases, having formed a second peak as the voltage scan also provides information about the reversibility of a reaction at a given scan rate (Bard \& Faulkner, 2001). There are two components to the current: (a) a capacitive component resulting from re-distribution of charged and polar species at the electrode surface (nonFaradaic process) and (b) a component resulting from exchange of electrons between the electrode and redox species immobilized at the electrode surface, or free in solution (Faradaic process) (Bard \& Faulkner, 2001). At sufficiently oxidizing or reducing potentials, where the ratio of electron transfer between the electrode and the redox species in solution is sufficiently fast, the Faradaic current is controlled by the rate of diffusion to the electrode. Hence, for the reversible reduction of redox species $\mathrm{O}$ :

$$
O+n e \leftrightarrow R
$$

With a redox potential $\mathrm{E}^{0}$, the Faradaic current, $\mathrm{i}_{\mathrm{f}}$, will depend on the concentration gradient of $\mathrm{O}$ at the electrode surface:

$$
i_{f}=n F A D_{0}\left(\frac{d[O]}{d x}\right) x=0
$$

where, $A$ is the area of the electrode, $D_{0}$ is the diffusion coefficient of $O, n$ is the number of electrons transferred and F is Faraday's constant. By holding the working electrode at a 
positive potential and then sweeping towards and beyond $\mathrm{E}^{0}$, the surface concentration of $\mathrm{O}$ will change in accordance with the Nernst equation:

$$
\frac{[O]}{[R]}=\exp \left[\frac{n F}{R T}\left(E-E^{0}\right)\right]
$$

where, $\mathrm{E}$ is the electrode potential, $\mathrm{R}$ is the gas constant and $\mathrm{T}$ is the temperature in Kelvins. The shape of the voltammogram for a given compound depends not only on the scan rate and the electrode surface, which is different after each adsorption step, but also depends on the catalyst concentration. For example, increasing the concentration of reaction specific enzymes at a given scan rate will result in a higher current compared to the non-catalyzed reaction (Tan et al., 2005).

The waveform of the voltage applied to a working electrode in CV is triangular shaped (i.e., the forward and reverse scan). Since, this voltage varies linearly with the time the scan rate is the slope $(\mathrm{V} / \mathrm{s})$. An example, of a $\mathrm{CV}$ for the reduction of ferricyanide to ferrocyanide $\left(\mathrm{K}_{4}\left[\mathrm{Fe}(\mathrm{CN})_{6}\right]^{4-} / \mathrm{K}_{3}\left[\mathrm{Fe}(\mathrm{CN})_{6}\right]^{3-}\right)$ is shown in Fig. $4 \mathrm{~b}$. The peak shape of the reductive and reverse oxidative current vs. electrode potential curve (i-E) in Fig. $4 \mathrm{~b}$ is typical of an electrode reaction in which the rate is governed by diffusion of the electroactive species to a planar electrode surface. That is the rate of the electron transfer step is fast compared to the rate at which ferricyanide is transported (diffuses) from the bulk solution to the electrode surface due to a concentration gradient, as ferricyanide is reduced to ferrocyanide. In such a case peak current, $i_{p}$, is governed by the Randle-Sevcik relationship:

$$
i_{p}=K n^{3 / 2} A D^{1 / 2} c^{b} v^{1 / 2}
$$

where the constant $\mathrm{K}=2.72 \times 10^{5}, \mathrm{n}$ is the number of moles of electrons transferred per mole of electroactive species (e.g., ferricyanide), A is the area of the electrode in $\mathrm{cm}^{2}, \mathrm{D}$ is the diffusion coefficient in $\mathrm{cm}^{2} / \mathrm{s}, \mathrm{c}^{\mathrm{b}}$ is the solution concentration in mole/l, and $v$ is the scan rate of the potential in $\mathrm{V} / \mathrm{s}$.

The $i_{p}$ is linearly proportional to the bulk concentration, $c^{b}$, of the electroactive species, and the square root of the scan rate, $v^{1 / 2}$. Thus, an important diagnostic is a plot of the $i_{p} v s . v^{1 / 2}$. If the plot is linear, it is reasonably safe to say that the electrode reaction is controlled by diffusion, which is the mass transport rate of the electroactive species to the surface of the electrode across a concentration gradient. The thickness $(\delta)$ of the diffusion layer can be approximated by $\delta \sim[D t]^{1 / 2}$, where $\mathrm{D}$ is the diffusion coefficient and $t$ is time in seconds. A quiet (i.e., unstirred solutions) is required. The presence of supporting electrolyte, such as $\mathrm{KNO}_{3}$ in this example, is required to prevent charged electroactive species from migrating in the electric field gradient (Bard \& Faulkner, 2001).

\subsection{Electrochemical impedance spectroscopy}

Electrochemical impedance spectroscopy (EIS) has long been established as a sensitive technique to monitor the electrical response of a solid/liquid system subjected to the application of a periodic small amplitude AC signal. Analysis of the system response provides information concerning the solid/liquid interface and on the eventual occurrence of reactions at this local region (MacDonald, 1987). EIS is a non-destructive steady-state technique that is capable of probing the relaxation phenomena over a range of frequencies (Bockris et al., 2000; Bard \& Faulkner, 2001; Macdonald, 1987). 
The power of EIS lies in its ability to provide in situ information on relaxation times over the frequency range $10^{6}$ to $10^{-4} \mathrm{~Hz}$. It is a tool that has been used to identify and separate different contributions to the electric and dielectric responses of the biosystems.

Impedance spectroscopy is a powerful method of analysing the complex electrical resistance of a system and is sensitive to surface phenomena and changes of bulk properties. The impedance $\mathrm{Z}$ of a system is generally determined by applying a voltage perturbation with small amplitude and detecting the current response. From this definition, the impedance $Z$ is the quotient of the voltage-time function $\mathrm{V}(\mathrm{t})$ and the resulting current-time function $\mathrm{I}(\mathrm{t})$ :

$$
Z=\frac{V(t)}{I(t)}=\frac{V_{0} \sin (2 \pi f t)}{I_{0} \sin (2 \pi f t+\phi)}=\frac{1}{Y}
$$

where $V_{0}$ and $I_{0}$ are the maximum voltage and current signals, $f$ is the frequency, $t$ the time, $\phi$ the phase shift between the voltage-time and current-time function, and $Y$ is the complex conductance or admittance. The impedance is a complex value, since the current can differ not only in terms of the amplitude but it can also show a phase shift $\phi$ compared to the voltage-time function. Thus, the value can be described either by the modulus $|Z|$ and the phase shift $\phi$ or alternatively by the real part $\mathrm{Zr}$ and the imaginary part $\mathrm{Zi}$ of the impedance. This is illustrated in Fig 5.

a

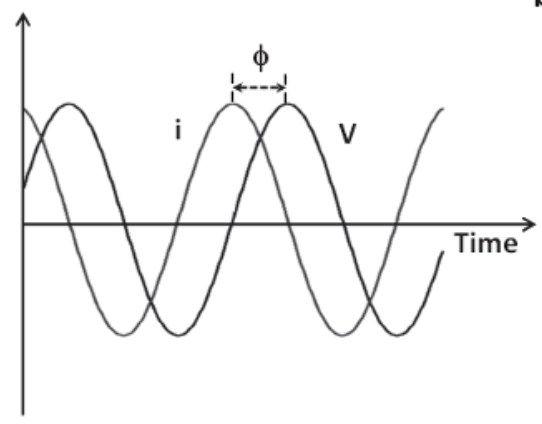

b

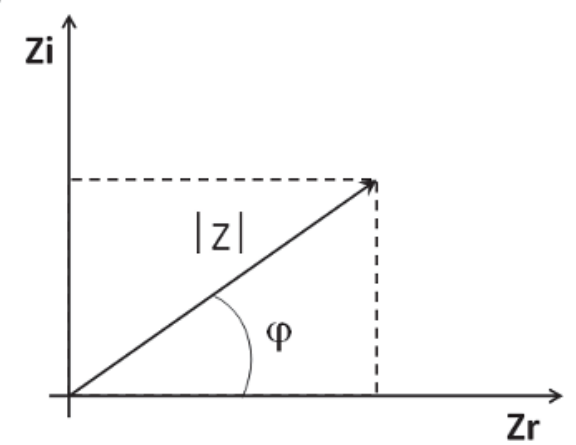

Fig. 5. Impedance is a complex value that is defined as the quotient of the voltage (time) and current (time) functions. It can be expressed as the modulus $|\mathrm{Z}|$ and the phase angle $\phi$, or it can be specified by the real $(\mathrm{Zr})$ and the imaginary $(\mathrm{Zi})$ parts of the impedance.

Therefore, the results of an impedance measurement can be illustrated in two different ways: using a Bode plot which plots $\log |\mathrm{Z}|$ and $\phi$ as a function of $\log \mathrm{f}$, or a Nyquist plot which plots $\mathrm{Zr}$ and $\mathrm{Zi}$. On the Nyquist plot the impedance (Fig. 6a) can be represented as a vector (arrow) of length $|Z|$. The angle between this vector and $x$-axis, commonly called the phase angle, is $\phi$ (=argZ).

Nyquist plots have one mayor shortcoming. When you look any data point on the plot, you cannot tell what frequency was used to record that point. This plot results from electrical circuit of Fig. 6b. Another popular representation method is the Bode plot. The impedance is plotted with log frequency on the $x$-axis and both the absolute values of the impedance $\left(|\mathrm{Z}|=\mathrm{Z}_{0}\right)$ and the phase-shift on the $\mathrm{x}$-axis. 
a

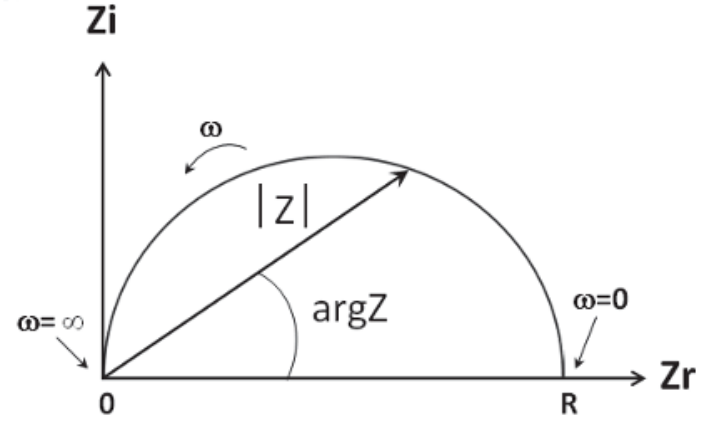

b

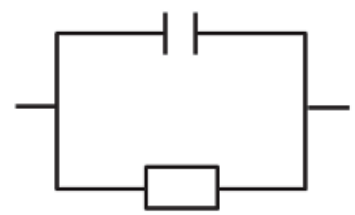

Fig. 6. Nyquist plot with impedance vector (a) and simple equivalent circuit with one time constant (b).

In the typical biosensor application of EIS, the biological component is immobilized on the working electrode and the interaction with an analyte molecule is detected. The impedance of the sensing electrode (the working electrode modified with the biological component) controls the overall impedance. Like all electrochemical biosensors, impedimetric sensors are bioelectronic devices that make use of the interactions of biomolecules with a conductive (or semiconducting) transducer surface. The detection process involves the formation of the recognition complex between the sensing biomolecule and the analyte at the interface electronic transducer, which directly or indirectly alters the electrical properties of the recognition surface.

\subsection{Electrochemical LDL biosensors}

Cyclic voltammetry can be used to monitor the molecular interaction and explore association between biomolecules and LDL based on the modification at anodic and cathodic peaks. Nicolini's group (Stura et al., 2007) improve the mechanical stability of electrodes based on P450scc for LDL-cholesterol detection and measure, using anodic porous alumina (APA). They have been shown, by means of CV measurements, that the sensitivity of the APA+P450scc system was slightly reduced with respect to the pure P450scc system, the readout was stable for a much longer period of time, and the measures remained reproducible inside a proper confidentiality band. To optimize the adhesion of P450scc to APA, a layer of poly-l-lysine, a poly-cation, was successfully implemented as intermediate organic structure. They obtained an optimization of the electron transfer's stability leading to the optimal detection of cholesterol in the clinical range concentration for longer times of use.

In another work, Nicolini's group (Antonini et al., 2004) employed Cytochrome P450sccK201E, mutated form of cytochrome P450scc native recombinant (P450sccNR), to study the enzyme-substrate interaction. The biochemical analysis was realized to observe the electrochemical responses of the engineerized enzyme to three different forms of cholesterol: free, LDL and high-density lipoproteins (HDL). The detection of the cholesterol was performed by electrochemical method using $\mathrm{CV}$ and chronoamperometry measurements. Compared to cytochrome P450sccNR, the cytochrome P450sccK201E displays a different behavior in the interaction with the substrate detection. The experimental data have shown that the mutation has improved the affinity between the 
cytochrome P450 and the substrates; in particular, the best responses were found in the detection of cholesterol in HDL. CV and chronoamperometry results showed that electrochemical response of the mutant P450sccK201E and P450sccNR can be utilized for the cholesterol detection.

Electrochemical methods associated with nanomaterials have been employed to develop electrochemical biosensor for the detection of LDL. More recently, a novel, sensitive, labelfree, LDL electrochemical biosensor was fabricated by adsorption of antibody to apoB-100. Yan et al. (2008) developed silver chloride/polyaniline (PANI) core-shell nanocomposites (AgCl/PANI) combined with gold nanoparticles (AuNPs) to prepare the AuNPsAgCl/PANI hybrid material. Yan et al. (2008) have been used a highly specific antibody, anti-apoB, that acts as a LDL receptor and fabricated an electrochemical biosensor by adsorption of anti-apoB on AuNPs-AgCl-polyaniline-modified glassy carbon electrode. The hybrid material could provide surface for high antibody loading due to its large surface-tovolume ratio. Since each LDL has an apoB-100 on its phospholipids coat, they could be bonded to the electrode surface through the specific antibody-antigen reaction. EIS was used to characterize the recognition of LDL. The negative charges carried by LDL phospholipids coat would block the electron transfer of the $\mathrm{K}_{4}\left[\mathrm{Fe}(\mathrm{CN})_{6}\right]^{4-} / \mathrm{K}_{3}\left[\mathrm{Fe}(\mathrm{CN})_{6}\right]^{3-}$ redox couple severely. In addition, the conductivity of LDL is very poor, so small amounts of LDL on the electrode could result in great change in the electron-transfer resistance. The biosensor exhibited a highly sensitive response to LDL with a detection limit of $0.34 \mathrm{pg} / \mathrm{ml}$.

In others studies, Langmuir-Blodgett (LB) films of polyaniline (PANI) were utilized for the fabrication of impedimetric immunosensor for detection of human plasma LDL by immobilizing anti-apoB via EDC-NHS coupling. Anti-apoB/PANI-stearic acid LB films immunoelectrodes studied by EIS spectroscopy revealed detection of LDL in the wide range of $0.018 \mu \mathrm{M}(6 \mathrm{mg} / \mathrm{dl})$ to $0.39 \mu \mathrm{M}(130 \mathrm{mg} / \mathrm{dl})$, covering the physiological range in blood, with a sensitivity of $11.25 \mathrm{k} \Omega \mu \mathrm{M}^{-1}$ (Matharu et al., 2010). Therefore, from the different types of biosensors discussed above we showed that the possibility to detect LDL and modified LDL by piezoelectric, optical or electrical techniques such as QCM, SPR, VC and EIS are strategic in clinical diagnostics.

\section{Conclusion and future trend}

Studies based on LDL biosensors have been directed to decrease the detection time and develop new ways of detecting LDL and modified LDL. The techniques discussed here can provide information on the steady state or dynamics of real time events. Therefore, the combined application of QCM, SPR, VC and EIS is a powerful tool to the development of new biosensors for LDL and modified LDL. The trend in the clinical laboratory is the development of biosensors for multiplex detection targets. A biosensor that simultaneously measures multiple analytes (e.g., HDL, LDL, VLDL, modified LDL, total cholesterol, triglycerides, C-reactive protein and others) in a single assay and gives information about the cardiovascular risk profile in few minutes is a great challenge and warrants more studies in this field.

\section{Acknowledgment}

The authors acknowledge the financial support of Fundação de Amparo à Ciência e Tecnologia do Estado de Pernambuco (FACEPE, grant to M.D.L.O.); Fundação de Amparo à 
Pesquisa do Estado de São Paulo (FAPESP, grant to D.S.P.A. and scholarship to V.R.H.); Conselho Nacional de Pesquisa e Desenvolvimento Científico (CNPq, grant to D.S.P.A.), Rede ELINOR de Nanobiotecnologia/CAPES (grant to M.D.L.O. and C.A.S.A.) and INCTif/CNPq (grant to D.S.P.A.).

\section{References}

Abdulhalim, I., Zourob, M. \& Lakhtakia, A. (2008). Surface Plasmon Resonance for Biosensing: A Mini-Review. Electromagnetics, Vol.28, Issue3, (April 2008) p.p. 214242, ISSN 0272-6343.

Annangudi, S.P., Deng, Y., Gu, X., Zhang, W., Crabb, J.W. \& Salomon, R.G. (2008). Lowdensity lipoprotein has an enormous capacity to bind (E)-4-hydroxynon-2-enal (HNE): detection and characterization of lysyl and histidyl adducts containing multiple molecules of HNE. Chemical Research in Toxicology, Vol.21, No.7, (June 2008), p.p. 1384-1395, ISSN: 0893-228X.

Antonini, M., Ghisellini, P., Paternolli, C. \& Nicolini, C. (2004). Electrochemical study of the interaction between cytochrome P450sccK201E and cholesterol. Talanta, Vol.62, Issue5, (April 2004), p.p. 945-950, ISSN 0039-9140.

Arnau, A. (2008). A Review of Interface Electronic Systems for AT-cut Quartz Crystal Microbalance Applications in Liquids. Sensors, Vol.8, (March 2008), p.p. 370-411, ISSN 1424-8220.

Asci, G., Basci, A., Shah, S.V., Basnakian, A., Toz, H., Ozkahya, M., Duman, S. \& Ok, E. (2008). Carbamylated low-density lipoprotein induces proliferation and increases adhesion molecule expression of human coronary artery smooth muscle cells. Nephrology, Vol.13, No.6, (June 2008), p.p. 480-486, ISSN: 0931-041X.

Bachorik, P.S. (1997). Measurement of low density lipoprotein cholesterol, In: Handbook of Lipoprotein Testing, Rifai, N., Warnick, G.R. \& Dominiczak, M.H. (Eds.), 145-160, AACC Press, ISBN 978-189-0883-35-5,Washington.

Bard, J. \& Faulkner, L.R. (2001). Electrochemical Methods: Fundamentals and Applications, 2nd edition, John Wiley and Sons, Inc., ISBN 978-047-1043-72-0, New York, United States of America.

Basta, G., Schmidt, A.M. \& De Caterina, R. (2004). Advanced glycation end products and vascular inflammation: implications for accelerated atherosclerosis in diabetes. Cardiovascular Research, Vol.63, No.4, p.p. 582-592, ISSN: 1755-3245.

Behm, E., Ivanovich, P. \& Klinkmann, H. (1989). Selective and Specific Adsorbents for Medical Therapy. The International Journal of Artificial Organs, 12, Issue1, (January 1989), p.p. 1-10, ISSN 0391-3988.

Bockris, J.O.M., Reddy, A.K.N. \& Gamboa-Aldeco, M. (2000). Modern Electrochemistry 2A: Fundamentals of Electrodics, 2nd edition, Vol.2, Klumer Academic/Plenum Publishers, ISBN 978-030-6461-67-5, New York, United States of America.

Bosch, T., Schmidt, B., Kleophas, W., Gillen, C., Otto, V., Passlick-Deetjen, J. \& Gurland, H.J. (1997). LDL Hemoperfusion-A New Procedure for LDL Apheresis: First Clinical Application of an LDL Adsorber Compatible with Human Whole Blood. Artificial Organs, Vol.21, Issue9 (June 1997), 977-982, ISSN 1525-1594.

Brett, C.M.A. \& Brett, A.M.O. (1993). Electrochemistry: Principles, Methods, and Applications, Oxford University Press, ISBN 978-019-8553-88-5, New York, United States of America. 
Brown, B.E., Rashid, I., Van Reyk, D.M. \& Davies, M.J. (2007). Glycation of low-density lipoprotein results in the time-dependent accumulation of cholesteryl esters and apolipoprotein B-100 protein in primary human monocyte-derived macrophages. FEBS Journal, Vol.274, No.6, (March 2007), p.p. 1530-1541, ISSN: 1742-464X.

Bunde, R.L., Jarvi, E.J. \& Rosentreter, J.J. (1998). Piezoelectric Quartz Crystal Biosensor. Talanta, vol.46, (August 1998), pp.1223-1236, ISSN 0039-9140.

Camejo, G., Hurt-Camejo, E., Wiklund, O. \& Bondjers, G. (1998). Association of apo B Lipoproteins with Arterial Proteoglycans: Pathological Significance and Molecular Basis. Atherosclerosis, Vol.139, (August 1998), p.p. 205-222, ISSN 0021-9150.

Choi, J.-W., Park, K.-S., Lee, W., Oh, B.-K., Chun, B.-S. \& Paek, S.-H. (2004). Regulation of anti-LDL Immobilization on Self-Assembled Protein G Layer using CHAPS and its Application to Immunosensor. Materials Science and Engineering C, Vol.24, Issues1-2, (October 2003), p.p. 241-245, ISSN 0928-4931.

Chunta, S., Promptmas, C. \& Cherdchu, C. (2009). Lipoprotein Sensor: A Piezoelectric Quartz Crystal Device. International Journal of Applied Biomedical Engineering, Vol.2, No.1, (July 2009), p.p. 24-32, ISSN 0973-4562.

Cooper, J.M. \& Cass, A.E.G. (2004). Biosensors - Pratical Approach, Oxford University Press, ISBN 978-019-9638-46-8, Oxford, Great Britain.

Cordova, C.M., Schneider, C.R., Juttel, I.D. \& Cordova, M.M. (2004). Comparison of LDLcholesterol direct measurement with the estimate using the Friedewald formula in a sample of 10,664 patients. Arquivos Brasileiros de Cardiologia, Vol.83, No.6, Issue482-7, (January 2004), p.p. 476-81, ISSN: 0066-782X.

Curie J. \& Curie P. (1880a). Développement, par Pression, de L'électricité Polaire dans les Cristaux Hémièdres à Faces Inclines. Comptes Rendus de l'Académie des sciences, Vol.91, p.p. 294-295, ISSN 0764-4469.

Curie J. \& Curie P. (1880b). Sur L'électricité Polaire dans les Cristaux Hémièdres à Faces Inclinées. Comptes rendus de l'Academie des Sciences, Vol.91, p.p. 383-386, ISSN 07644469.

D’Ulivo, L., Saint-Guirons, J., Ingemarsson, B. \& Riekkola, M.-L. (2010). Quartz Crystal Microbalance, a Valuable Tool for Elucidation of Interactions between apoB-100 Peptides and Extracellular Matrix Components. Analytical and Bioanalytical Chemistry, Vol.396, (December 2009), p.p. 1373-1380, ISSN 1618-2642.

D’Ulivo, L., Witos, J., Öörni, K., Kovanen, P.T. \& Riekkola, M.-L. (2009). Capillary Electrochromatography: a Tool for Mimicking Collagen Surface Interactions with Apolipoprotein B-100 Peptides. Electrophoresis, Vol.30, (October 2009), p.p. 38383845, ISSN 0173-0835.

Daghestani, H.N. \& Day, B.W. (2010). Theory and Applications of Surface Plasmon Resonance, Resonant Mirror, Resonant Waveguide Grating, and Dual Polarization Interferometry Biosensors. Sensors, Vol.10, Issue10, (November 2010) p.p. 96309646, ISSN 1424-8220.

Damasceno, N.R., Sevanian, A., Apolinario, E., Oliveira, J.M., Fernandes, I., \& Abdalla, D.S.P. (2006). Detection of electronegative low density lipoprotein (LDL-) in plasma and atherosclerotic lesions by monoclonal antibody-based immunoassays. Clinical Biochemistry, Vol.39, No.1, (November 2005), p.p. 28-38, ISSN: 0009-9120. 
Damos, F.S., Mendes, R.K. \& Kubota, L.T. (2004). Applications of QCM, EIS and SPR in the Investigation of Surfaces and Interfaces for the Development of (Bio)Sensors, Química Nova, Vol.27, No.6, (December 2004) p.p. 970-979, ISSN 1678-7064.

Esteban-Salan, M., Aguilar-Doreste, J.A., Arranz-Pena, M.L., Juve-Cuxart, S., Gich-Salarich, I., Zapico-Muniz, E. \& Ordonez-Llanos, J. (2008). Multicentric evaluation of the homogeneous LDL-cholesterol Plus assay: comparison with beta-quantification and Friedewald formula. Clinical Biochemistry, Vol.41, No.16-17, (August 2008), p.p. 1402-1409, ISSN: 0009-9120.

Faulin, T.E.S., Sena, K.C.M., Telles, A.E.R., Grosso, D.M., Faulin, E.J.B. \& Abdalla, D.S.P. (2008). Validation of a novel ELISA for measurement of Electronegative LDL. Clinical Chemistry and Laboratory Medicine, Vol.46, No.12, (August 2008), p.p. 17691775, ISSN: 1434-6621.

Fowler, J.M., Wong, D.K.Y., Halssal, H.B. \& Heineman, W.R. (2008). Recent Developments in Electrochemical Immunoassays and Immunosensors, In: Electrochemical Sensors, Biosensors and their Biomedical Applications, Zhang, X., Ju, H. \& Wang, J. (Eds.), 115140, Academic Press Elsevier Inc., ISBN 978-012-3737-38-0, United States of America.

Freire, R.S., Thongngamdee, S., Duran, N., Wang, J. \& Kubota, L.T. (2002). Mixed Enzyme (Laccase/Tyrosinase)-based Remote Electrochemical Biosensor for Monitoring Phenolic Compounds. Analyst, Vol.127, Issue2, p.p. 258-261, ISSN 0003-2654.

Friedewald, W.T., Levy, R.I. \& Fredrickson, D.S. (1972). Estimation of the Concentration of Low-Density Lipoprotein Cholesterol in Plasma, without use of the Preparative Ultracentrifuge. Clinical Chemistry, Vol.18, (March 1972), p.p. 499-502, ISSN 15308561.

Gaus, K. \& Hall, E.A.H. (2003). Short Peptide Receptor Mimics for Atherosclerosis Risk Assessment of LDL. Biosensors and Bioelectronics, Vol.18, (March 2003), p.p. 151-164, ISSN 0956-5663.

Green, R.J., Frazier, R.A., Shakesheff, K.M., Davies, M.C., Roberts, C.J. \& Tendler, S.J.B. (2000). Surface Plasmon Resonance Analysis of Dynamic Biological Interactions with Biomaterials. Biomaterials, Vol.21, Issue18, (September 2000) p.p. 1823-1835, ISSN 0142-9612.

Hansson, G.K., \& Libby, P. (2006). The immune response in atherosclerosis: a double-edged sword. Nature Reviews Immunology, Vol.6, No.7, (July 2006), p.p. 508-519, ISSN: 1474-1733.

Miller, Y.I., Choi, S.H., Fang, L. \& Tsimikas, S. (2010). Lipoprotein modification and macrophage uptake: role of pathologic cholesterol transport in atherogenesis, In: Cholesterol binding and cholesterol transport proteins. Structure and function in health and disease, Harris, J.R., pp. 229-251, Springer, ISBN 978-90-481-8621-1, Dordrecht, Heidelberg, London and New York.

Hedrick, C.C., Thorpe, S.R., Fu, M.-X., Harper, C.M., Yoo, J., Kim, S.-M., Wong, H. \& Peters, A.L. (2000). Glycation Impairs High-Density Lipoprotein Function. Diabetologia, Vol.43, (March 2000), p.p. 312-320, ISSN 0012-186X.

Helali, S., Ben Fredj, H., Cherif, K., Abdelghani, A., Martelet, C. \& Jaffrezic-Renault, N. (2008). Surface Plasmon Resonance and Impedance Spectroscopy on Gold Electrode for Biosensor Application. Materials Science and Engineering: C, Vol.28, Issue5-6, (July 2008) p.p. 588-593, ISSN 0928-4931. 
Hodgkinson, C.P., Laxton, R.C., Patel, K. \& Ye, S. (2008). Advanced glycation end-product of low density lipoprotein activates the Toll-like 4 receptor pathway implications for diabetic atherosclerosis. Arteriosclerosis, Thrombosis, and Vascular Biology, Vol.28, No.12, (September 2008), p.p.2275-2281, ISSN: 1079-5642.

Homola, J., Yee, S.S. \& Gauglitz, G. (1999). Surface Plasmon Resonance Sensors: Review. Sensors and Actuators B, Vol.54, Issues1-2, (January 1999) p.p. 3-15, ISSN 0925-4005.

Höök, F. \& Rudh, M. (2005). Quartz Crystal Microbalances (QCM) in Biomacromolecular Recognition. Biotech International, Vol.2, (March 2005), p.p. 1-5, ISSN 2032-2887.

Ishigaki, T., Ohki, I., Utsunomiya-Tate, N. \& Tate, S.-I. (2007). Chimeric Structural Stabilities in the Coiled-Coil Structure of the NECK Domain in Human Lectin-Like Oxidized Low-Density Lipoprotein Receptor 1 (LOX-1). The Journal of Biochemistry, Vol.141, Issue6, (March 2007), p.p. 855-866, ISSN 0021-924X.

Itabe, H. \& Ueda, M. (2007). Measurement of plasma oxidized low-density lipoprotein and its clinical implications. Journal of atherosclerosis and thrombosis, Vol.14, No.1, (February 2007), p.p. 1-11, ISSN: 1340-3478.

Jambunathan, K. \& Hillier, A.C. (2003). Measuring Electrocatalytic Activity on a Local Scale with Scanning Differential Electrochemical Mass Spectrometry. Journal of the Electrochemical Society, Vol.150, No.6, (June 2003), E312-E320, ISSN 0013-4651.

Johnson, P.B. \& Christy, R.W. (1972). Optical Constants of the Noble Metals, Physical Review B, Vol.6, Issue12, (December 1972) p.p. 4370-4379, ISSN 1098-0121.

Kanazawa, K.K. \& Gordon II, J.G. (1985). Frequency of a Quartz Microbalance in Contact with Liquid. Analytical Chemistry, Vol.57, Issue8, (July 1985), p.p. 1770-1771, ISSN 1177-3901.

Kretschmann, E. \& Raether, H. (1968). Radiative Decay of Non-Radiative Surface Plasmons Excited by Light. Zeitschrift für Naturforschung B, Vol.23A, p.p. 2135-2136, ISSN 0932-0776.

Kudo, Y., Fukuchi, Y., Kumagai, T., Ebina, K. \& Yokota, K. (2001). Oxidized Low-Density Lipoprotein-Binding Specificity of Asp-hemolysin from Aspergillus fumigates. Biochimica et Biophysica Acta, Vol.1568, (December 2001), p.p. 183-188, ISSN 03044165.

Laffont, I., Shuvaev, V.V., Briand, O., Lestavel, S., Barbier, A., Taniguchi, N., Fruchart, J.-C., Clavey, V. \& Siest, G. (2002). Early-Glycation of Apolipoprotein E: Effect on its Binding to LDL Receptor, Scavenger Receptor A and Heparan Sulfates. Biochimica et Biophysica Acta, Vol.1583, (June 2002) p.p. 99- 107, ISSN 0304-4165.

Levitan, I., Volkov, S. \& Subbaiah, P.V. (2010). Oxidized LDL: Diversity, Patterns of Recognition, and Pathophysiology. Antioxidants \& Redox Signaling, Vol.13, No.1, (July 2010), p.p. 39-75, ISSN: 1523-0864.

Libby, P., Ridker, P.M., \& Hansson, G.K. (2009). Leducq Transatlantic Network on Atherothrombosis. Inflammation in atherosclerosis: from pathophysiology to practice. Journal of the American College of Cardiology, Vol.54, No.23, (December 2009), p.p. 2129-2138, ISSN: 0735-1097.

Liu, D., He, B., Han, S., Wang, S., Liu, Q., Jun-ichic, A., Osa, T. \& Chen, Q. (2007). An Adsorption Behavior of low-Density Lipoprotein onto Cholesterol-Modified Dextran Studied by a Quartz Crystal Microbalance. Materials Science and Engineering: C, Vol.27, Issue4, (May 2007), p.p. 665-669, ISSN 0928-4931. 
Lundstrom I. (1994). Real-Time Biospecific Interaction Analysis. Biosensors and Bioelectronics, Vol.9, Issues9-10, (January 2002), pp. 725-736, ISSN 0956-5663.

Luppa, P.B., Sokoll, L.J. \& Chan, D.W. (2001). Immunosensor principles and applications to clinical chemistry. Clinica Chimica Acta, Vol.314, Issue1-2, (December 2001), p.p. 126.

Macdonald, J.R. (1987). Impedance spectroscopy: emphasizing solid materials and systems, John Wiley and Sons, Inc., ISBN 978-047-1831-22-8, New York, United States of America.

Malhotra, B.D., Chaubey, A. \& Singh, S.P. (2006). Prospects of Conducting Polymers in Biosensors. Analytica Chimica Acta, 2006, Vol.578, Issue1, (September 2006), p.p. 5974, ISSN 0003-2670.

Malle, E., Marsche, G., Arnhold, J. \& Davies, M.J. (2006). Modification of low-density lipoprotein by myeloperoxidase-derived oxidants and reagent hypochlorous acid. Biochimica et Biophysica Acta, Vol.1761, No.4, (April 2006), p.p. 392-415, ISSN: 03044165.

Mamo, J.C.L., Szeto, L. \& Steiner, G. (1990). Glycation of Very Low Density Lipoprotein from Rat Plasma Impairs its Catabolism. Diabetologia, Vol.33, No.6, (June 1990), p.p. 339-345, ISSN 0012-186X.

Marshall, W.J. \& Bangert, S.K. (2008). Clinical chemistry, Mosby Elsevier, ISBN 9780723434559, Philadelphia.

Marx, K.A. (2003). Quartz Crystal Microbalance: A Useful Tool for Studying Thin Polymer Films and Complex Biomolecular Systems at the Solution-Surface Interface. Biomacromolecules, Vol.4, No.5, (October 2002), p.p. 1099-1120, ISSN 1525-7797.

Matharu, Z., Bandodkar, A.J., Sumana, G., Solanki, P.R., Ekanayake, E.M., Kaneto, K., Gupta, V. \& Malhotra, B.D. (2009a) Low Density Lipoprotein Detection Based on Antibody Immobilized Self-Assembled Monolayer: Investigations of Kinetic and Thermodynamic Properties. The Journal of Physical Chemistry B, Vol.29, No.118, Issue43, (October 2009), p.p. 14405-14412, ISSN 1089-5647.

Matharu, Z., Sumana, G., Gupta, V. \& Malhotra, B.D. (2010). Langmuir-Blodgett films of polyaniline for low density lipoprotein detection. Thin Solid Films, Vol.519 (August 2010) p.p. 1110-1114, ISSN 040-6090.

Matharu, Z., Sumana, G., Pandey, M.K., Gupta, V. \& Malhotra, B.D. (2009b) Low Density Lipoprotein Sensor Based on Surface Plasmon Resonance. Thin Solid Films, Vol.518, Issue2, (November 2009) p.p. 719-723, ISSN 0040-6090.

Matsuura, E., Hughes, G.R. \& Khamashta, M.A. (2008). Oxidation of LDL and its clinical implication. Autoimmunity Reviews, Vol.7, No.7, (July 2008), p.p. 558-566, ISSN: 1568-9972.

McGill, H.C. Jr, McMahan, C.A., Herderick, E.E., Malcom, G.T., Tracy, R.E. \& Strong, J.P. (2000). Origin of atherosclerosis in childhood and adolescence. The American Journal of Clinical Nutrition, Vol.72, No.5, (November 2000), p.p. 1307S-1315S, ISSN: 00029165.

Novotny, L. \& Hecht, B. (2006). Principles of Nano-Optics, Cambridge University Press, ISBN 978-052-1832-24-3, Cambridge, UK.

Ohki, I., Amida, H., Yamada, R., Sugihara, M., Ishigaki, T. \& Tate, S.-I. (2011). Surface Plasmon Resonance Study on Functional Significance of Clustered Organization of Lectin-like Oxidized LDL Receptor (LOX-1). Biochimica et Biophysica Acta, in press, ISSN 1570-9639. 
Oliveira, M.D.L., Correia, M.T.S. \& Diniz, F.B. (2009). Concanavalin A and Polyvinyl Butyral use as a Potential Dengue Electrochemical Biosensor. Biosensors and Bioelectronics, Vol.25, Issue4, (December 2009), pp. 728-732, ISSN 0956-5663.

Oliveira, M.D.L., de Melo, C.P., Glaucius, O. \& Andrade, C.A.S. (2011). Development of Impedimetric and Optical Calcium Biosensor by Using Modified Gold Electrode with Porcine S100A12 protein. Colloids and Surfaces B - Biointerfaces, Vol.82, Issue2, (February 2011), p.p. 365-370, ISSN 0927-7765.

Otto, A. (1968). Excitation of Surface Plasma Waves in Silver by the Method of Frustrated Total Reflection. Zeitschrift für Physik, Vol.216, p.p. 398-410, ISSN 0340-2347.

Prassl, R. \& Laggner, P. (2009). Molecular structure of low density lipoprotein: current status and future challenges. European Biophysical Journal, Vol.38, No.2, (September 2008), p.p. 145-158, ISSN: 0175-7571.

Raether, H. (1988). Surface Plasmons on Smooth and Rough Surfaces and on Gratings, SpringerVerlag, ISBN 978-038-7173-63-4, Berlin.

Rifai, N., Iannotti, E., DeAngelis, K. \& Law, T. (1998). Analytical and clinical performance of a homogeneous enzymatic LDL-cholesterol assay compared with the ultracentrifugation-dextran sulfate-Mg2+ method. Clinical Chemistry, Jun;Vol.44, No.6, p.p. 1242-1250, ISSN: 1530-8561.

Robbio, L.L., Uboldi, P., Marcovina, S., Revoltella, R.P. \& Catapano, A.L. (2001). Epitope Mapping Analysis of Apolipoprotein B-100 using a Surface Plasmon ResonanceBased Biosensor. Biosensors and Bioelectronics, Vol.16 (February 2001), p.p. 963-969, ISSN 0956-5663.

Sauerbrey, G. (1959). Verwendung von Schwingquarzen zur Wägung dünner Schichten und zur Mikrowägung. Zeitschrift für Physik, Vol.155, Issue2, (April 1959), p.p. 206-222, ISSN 0340-2347.

Sawamura, T., Kume, N., Aoyama, T., Moriwaki, H., Hoshikawa, H., Aiba, Y., Tanaka, T., Miwa, S., Katsura, Y., Kita, T. \& Masaki, T. (1997). An Endothelial Receptor for Oxidized Low-Density Lipoprotein. Nature, Vol.386, (March 1997), p.p. 73-77, ISSN 0028-0836.

Schumaker, V.N., Phillips, M.L. \& Chatterton, J.E. (1994). Apolipoprotein B and LowDensity Lipoprotein Structure: Implications for Biosynthesis of Triglyceride-Rich Lipoproteins, In: Advances in Protein Chemistry, Anfinsen, C.B., Edsall, J.T., Richards, F.M. \& Eisenberg, D.S. (Eds.), 205-248, Calif. Academic Press, ISBN 978-012-034247-1, San Diego.

Skålén, K., Gustafsson, M., Rydberg, E.K., Hultén, L.M., Wiklund, O., Innerarity, T.L. \& Borén, J. (2002). Subendothelial Retention of Atherogenic Lipoproteins in Early Atherosclerosis. Nature, Vol.417, (June 2002), p.p. 750-754, ISSN 0028-0836.

Smith, A. (2008). The Quartz Crystal Microbalance, In: Handbook of Thermal Analysis and Calorimetry, Brown, M. \& Gallagher, P. (Eds.), 133-169, Vol.5, Elsevier B.V., ISBN 978-044-4531-23-0, Amsterdam.

Smith, E.A. \& Corn, R.M. (2003). Surface Plasmon Resonance Imaging as a Tool to Monitor Biomolecular Interactions in an Array Based Format, Applied Spectroscopy, Vol.57, No.11, (November 2003), p.p. 320A-332A, ISSN 0003-7028.

Snellings, S., Fuller, J., Pitner, M. \& David, P.W. (2003). An Acoustic Wave Biosensor for Human Low-Density Lipoprotein Particles: Construction of Selective Coatings. 
Biosensors and Bioelectronics, Vol.19, Issue4, (December 2003), p.p. 353-363, ISSN 0956-5663.

Srivastava, A.K. \& Sakthivel, P. (2001). Quartz-Crystal Microbalance Study for Characterizing Atomic Oxygen in Plasma Ash Tools. Journal of Vacuum Science \& Technology A, Vol.19, Issue1, (January 2001), p.p. 97-100 ISSN 1520-8567.

Stefan, R.I., van Staden, J.F. \& Aboul-Enein, H.Y. (2000). Immunosensor in clinical analysis. Fresenius Journal of Analytical Chemistry, 366 (December 1999) p.p. 659-668, ISSN 0937-0633.

Stocker, R. \& Keaney, J.R. (2004). Role of oxidative modifications in atherosclerosis. Physiological Reviews, Vol.84, No.4, (October 2004), p.p. 1381-1478, ISSN: 0031-9333.

Stura, E., Bruzzese, D., Valerio, F., Grasso, F., Perlo, P. \& Nicolini, C. (2007). Anodic Porous Alumina as Mechanical Stability Enhancer for LDL-Cholesterol Sensitive Electrodes. Biosensors and Bioelectronics, Vol.23, (July 2007), p.p. 655-660, ISSN 09565663.

Tan, X., Li, M., Cai, P., Luo, L. \& Zou, X. (2005). An Amperometric Cholesterol Biosensor Based on Multivalent Carbon Nanotubes and Organically Modified SolGel/Chitosan Hybrid Composite Film. Analytical Biochemistry, Vol.337, Issue1, (February 2005), p.p. 111-120, ISSN 1096-0309.

Thevenot, D.R., Toth, K., Durst, R.A. \& Wilson, G.S. (1999). Electrochemical Biosensors: Recommended Definitions and Classification. Pure and Applied Chemistry, Vol.71, No.12, (January 2001), p.p. 2333-2348, ISSN 1365-3075.

Tudos, A.J. \& Schasfoort, R.B.M. (2008). Introduction to Surface Plasmon Resonance, In: Handbook of Surface Plasmon Resonance, Tudos, A.J. \& Schasfoort, R.B.M. (Eds.), 1-14, RSC Publishing, ISBN 978-085-4042-67-8, Cambridge UK.

Viigimaa, M., Abina, J., Zemtsovskaya, G., Tikhaze A, Konovalova, G., Kumskova, E. \& Lankin, V. (2010). Malondialdehyde-modified low density lipoproteins as biomarker for atherosclerosis. Blood Pressure, Vol.19, No.3, (June 2010), p.p. 164-168, ISSN: 0803-7051.

Wood, R.W. (1902). On a Remarkable Case of Uneven Distribution of Light in a Diffraction Grating Spectrum. Proceedings of the Physical Society of London, Vol.18, No.1, p.p. 269275, ISSN 0370-1328.

Yan, W., Chen, X., Li, X., Feng, X. \& Zhu, J.-J. (2008). Fabrication of a Label-Free Electrochemical Immunosensor of Low-Density Lipoprotein. The Journal of Physical Chemistry B, Vol.112, No.4, (January 2008), p.p. 1275-1281, ISSN 1089-5647.

Yang, C.Y., Chen, S.H., Gianturco, S.H., Bradley, W.A., Sparrow, J.T., Tanimura, M., Li, W.H., Sparrow, D.A., DeLoof, H., Rosseneu, M., Lee, F.S., Gu, Z.W., Gotto, A.M.Jr. \& Chan, L. (1986). Sequence, Structure, Receptor-Binding Domains and Internal Repeats of Human Apolipoprotein B-100. Nature, Vol.323, (October 1986), p.p. 738742, ISSN 0028-0836.

Zhao, H. \& Ju, H. (2006). Multilayer Membranes for Glucose Biosensing via Layer-by-Layer Assembly of Multiwall Carbon Nanotubes and Glucose Oxidase. Analytical Biochemistry, Vol.350, Issue1, (March 2006), p.p. 138-144, ISSN 1096-0309. 


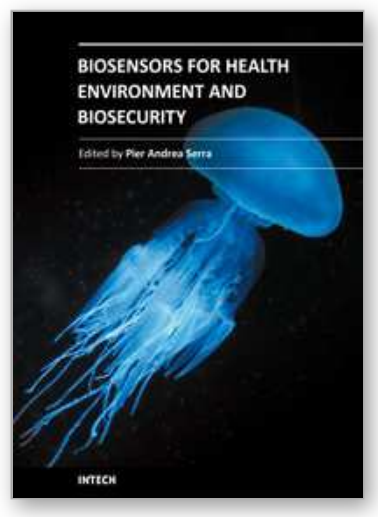

\author{
Biosensors for Health, Environment and Biosecurity \\ Edited by Prof. Pier Andrea Serra
}

ISBN 978-953-307-443-6

Hard cover, 540 pages

Publisher InTech

Published online 19, July, 2011

Published in print edition July, 2011

\begin{abstract}
A biosensor is a detecting device that combines a transducer with a biologically sensitive and selective component. Biosensors can measure compounds present in the environment, chemical processes, food and human body at low cost if compared with traditional analytical techniques. This book covers a wide range of aspects and issues related to biosensor technology, bringing together researchers from 16 different countries. The book consists of 24 chapters written by 76 authors and divided in three sections: Biosensors Technology and Materials, Biosensors for Health and Biosensors for Environment and Biosecurity.
\end{abstract}

\title{
How to reference
}

In order to correctly reference this scholarly work, feel free to copy and paste the following:

Cesar Andrade, Maria Danielly Oliveira, Tanize Faulin, Vitor Hering and Dulcineia Saes Parra Abdalla (2011). Biosensors for detection of Low-Density Lipoprotein and its modified forms, Biosensors for Health, Environment and Biosecurity, Prof. Pier Andrea Serra (Ed.), ISBN: 978-953-307-443-6, InTech, Available from: http://www.intechopen.com/books/biosensors-for-health-environment-and-biosecurity/biosensors-fordetection-of-low-density-lipoprotein-and-its-modified-forms

\section{INTECH}

open science | open minds

\section{InTech Europe}

University Campus STeP Ri

Slavka Krautzeka 83/A

51000 Rijeka, Croatia

Phone: +385 (51) 770447

Fax: +385 (51) 686166

www.intechopen.com

\section{InTech China}

Unit 405, Office Block, Hotel Equatorial Shanghai

No.65, Yan An Road (West), Shanghai, 200040, China 中国上海市延安西路65号上海国际贵都大饭店办公楼 405 单元

Phone: +86-21-62489820

Fax: $+86-21-62489821$ 
(C) 2011 The Author(s). Licensee IntechOpen. This chapter is distributed under the terms of the Creative Commons Attribution-NonCommercialShareAlike-3.0 License, which permits use, distribution and reproduction for non-commercial purposes, provided the original is properly cited and derivative works building on this content are distributed under the same license. 